\title{
Increased smoking and e-cigarette use among Irish teenagers: a new threat to Tobacco Free Ireland 2025
}

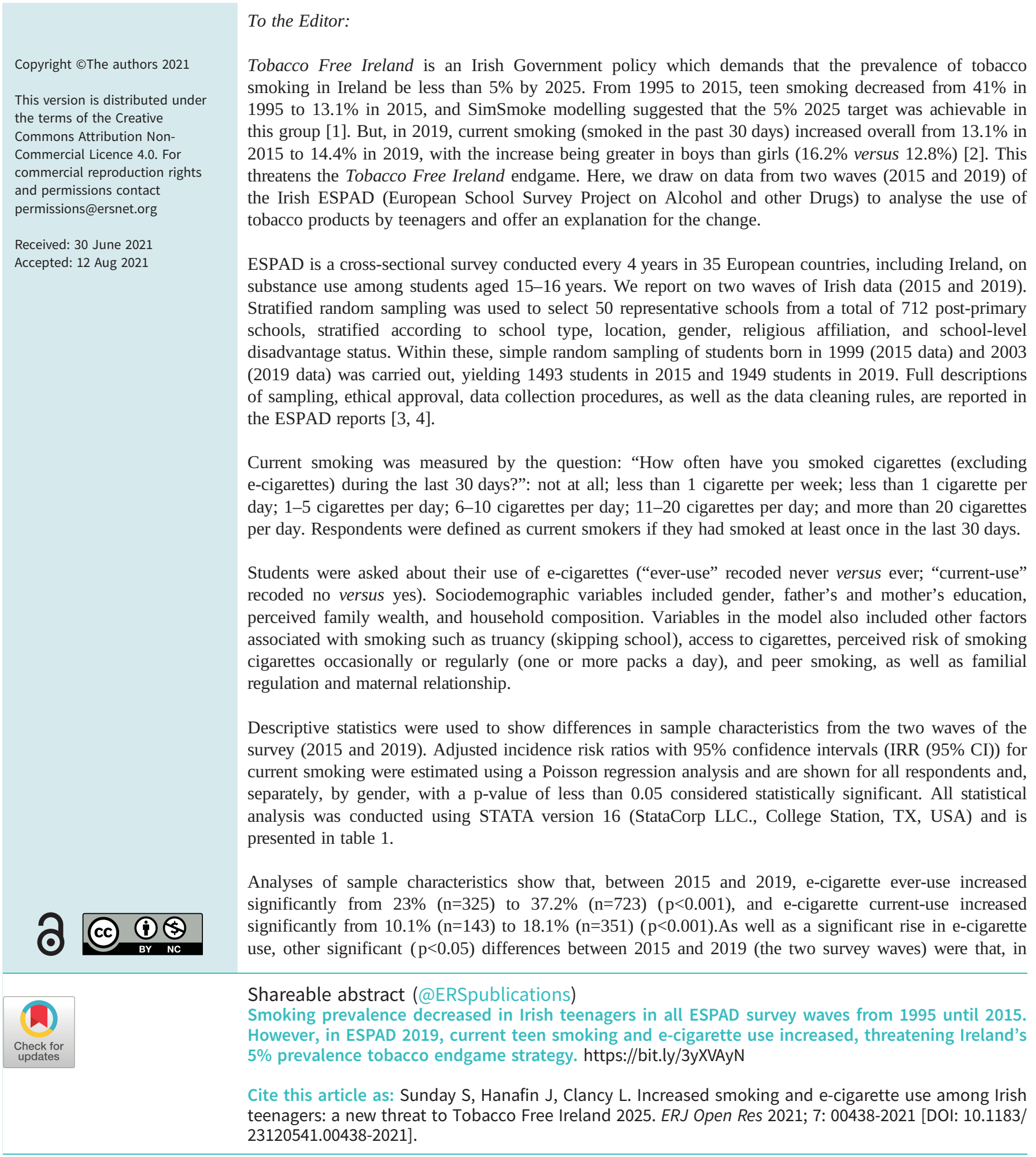


TABLE 1 Sample characteristics and Poisson regression results (adjusted incidence risk ratios (IRR)) of factors associated with current smoking in 16-year-olds, based on data from the Irish 2015 and 2019 ESPAD surveys

Sample characteristics

$2015 \quad 2019$

n (\%) n (\%)
Poisson regression results current smoking

Total adjusted IRR Male adjusted IRR

$(95 \% \mathrm{Cl})$
Female adjusted IRR

$(95 \% \mathrm{Cl})$

\begin{tabular}{|c|c|c|c|c|c|}
\hline \multicolumn{6}{|l|}{ Year } \\
\hline 2015 & 1472 & & 1 & 1 & 1 \\
\hline 2019 & & 1947 & $0.91(0.85-0.98)^{\star}$ & $0.91(0.82-1.00)$ & $0.95(0.86-1.05)$ \\
\hline \multicolumn{6}{|l|}{ Gender } \\
\hline Male & $752(51.1)$ & $946(48.5)$ & 1 & & \\
\hline Female & $720(48.9)$ & $1003(51.4)$ & $1.00(0.93-1.07)$ & $\mathrm{N} / \mathrm{A}$ & N/A \\
\hline \multicolumn{6}{|l|}{ Ever-used e-cigarettes } \\
\hline No & $1088(77.0)$ & $1219(62.7)^{\star}$ & 1 & 1 & 1 \\
\hline Yes & $325(23.0)$ & $723(37.2)$ & $1.27(1.16-1.40)^{\star}$ & $1.33(1.17-1.51)^{\star}$ & $1.27(1.11-1.45)^{*}$ \\
\hline \multicolumn{6}{|l|}{ Current use e-cigarettes } \\
\hline No & $1270(89.9)$ & $918(84.5)^{\star}$ & 1 & 1 & 1 \\
\hline Yes & $143(10.1)$ & $351(18.1)$ & $1.45(1.31-1.61)^{\star}$ & $1.39(1.21-1.60)^{\star}$ & $1.49(1.26-1.75)^{*}$ \\
\hline \multicolumn{6}{|l|}{ Father's education } \\
\hline Primary/some secondary school & $388(30.0)$ & $407(21.5)^{\star}$ & 1 & 1 & 1 \\
\hline Completed secondary school & $273(19.0)$ & $345(18.2)$ & $0.94(0.84-1.05)$ & $0.97(0.84-1.13)$ & $0.92(0.79-1.08)$ \\
\hline College/university & $600(41.7)$ & $897(47.4)$ & $0.95(0.87-1.04)$ & $1.00(0.87-1.15)$ & $0.91(0.80-1.04)$ \\
\hline Don't know or N/A & $177(12.3)$ & $244(13.0)$ & $0.99(0.86-1.15)$ & $1.01(0.81-1.26)$ & $1.01(0.83-1.23)$ \\
\hline \multicolumn{6}{|l|}{ Mother's education } \\
\hline Primary/some secondary school & $212(14.7)$ & $215(11.3)^{\star}$ & 1 & 1 & 1 \\
\hline Completed secondary school & $375(26.1)$ & $375(19.7)$ & $0.98(0.87-1.11)$ & $1.01(0.84-1.21)$ & $0.93(0.79-1.11)$ \\
\hline College/university & $719(50.0)$ & $1140(60.0)$ & $0.99(0.89-1.11)$ & $0.98(0.83-1.16)$ & $0.98(0.84-1.15)$ \\
\hline Don't know or N/A & $132(9.2)$ & 169 (8.9) & $0.92(0.77-1.10)$ & $0.92(0.71-1.18)$ & $0.92(0.70-1.21)$ \\
\hline \multicolumn{6}{|l|}{ Perceived wealth } \\
\hline About the same & $696(48.7)$ & $815(43.3)^{\star}$ & 1 & 1 & 1 \\
\hline Much better off & $223(15.6)$ & $308(16.4)$ & $1.09(0.98-1.20)$ & $1.14(0.99-1.31)$ & $1.04(0.89-1.21)$ \\
\hline Better off & $370(25.9)$ & $580(30.8)$ & $1.00(0.91-1.08)$ & $1.00(0.89-1.13)$ & $1.00(0.88-1.13)$ \\
\hline Less well off & $141(9.9)$ & $179(9.5)$ & $1.16(1.04-1.30)$ & $1.17(1.00-1.37)$ & $1.13(0.96-1.33)$ \\
\hline \multicolumn{6}{|l|}{ Household composition } \\
\hline Single parent & $262(17.8)$ & $371(19.0)^{\star}$ & 1 & 1 & 1 \\
\hline Two parents & $1109(75.3)$ & $1490(76.4)$ & $0.90(0.83-0.98)^{\star}$ & $0.88(0.78-0.99)^{\star}$ & $0.93(0.82-1.05)$ \\
\hline Blended family & $101(6.9)$ & $88(4.5)$ & $0.84(0.71-0.99)^{\star}$ & $0.87(0.68-1.11)$ & $0.81(0.64-1.03)$ \\
\hline \multicolumn{6}{|l|}{ Familial regulation } \\
\hline Know always & $906(62.7)$ & $1194(63.2)$ & 1 & 1 & 1 \\
\hline Know quite often & $337(23.3)$ & $455(24.1)$ & $0.97(0.89-1.06)$ & $0.97(0.86-1.09)$ & $0.97(0.86-1.10)$ \\
\hline Know sometimes & $128(8.9)$ & $166(8.8)$ & $1.16(1.04-1.30)$ & $1.15(0.98-1.34)$ & $1.16(0.98-1.38)$ \\
\hline Usually don't know & $73(5.1)$ & $74(3.9)$ & $1.25(1.07-1.45)^{\star}$ & $1.28(1.06-1.53)^{\star}$ & $1.23(0.92-1.63)$ \\
\hline \multicolumn{6}{|l|}{ Relationship with mother } \\
\hline Satisfied & $1251(87.5)$ & $1621(86.4)$ & 1 & 1 & 1 \\
\hline Neither nor & $74(5.2)$ & $106(5.6)$ & $1.01(0.87-1.16)$ & $0.95(0.77-1.18)$ & $1.06(0.87-1.28)$ \\
\hline Not satisfied & $105(7.3)$ & $150(8.0)$ & $1.04(0.92-1.17)$ & $0.99(0.82-1.18)$ & $1.10(0.93-1.31)$ \\
\hline \multicolumn{6}{|l|}{ Skipping school } \\
\hline None & $984(80.1)$ & $1309(79.6)$ & 1 & 1 & 1 \\
\hline $1-4$ days & $198(16.1)$ & $286(17.4)$ & $1.17(1.07-1.27)^{\star}$ & $1.17(1.03-1.32)^{\star}$ & $1.16(1.03-1.32)^{*}$ \\
\hline 5 days + & $47(3.8)$ & $50(3.0)$ & $1.53(1.32-1.78)^{\star}$ & $1.61(1.33-1.96)^{\star}$ & $1.46(1.14-1.86)^{\star}$ \\
\hline \multicolumn{6}{|l|}{ Access to cigarettes } \\
\hline Difficult & $348(24.1)$ & $551(28.4)^{\star}$ & 1 & 1 & 1 \\
\hline Easy & $893(61.8)$ & $1188(61.3)$ & $1.07(0.98-1.18)$ & $1.09(0.95-1.24)$ & $1.06(0.94-1.20)$ \\
\hline Do not know & $205(14.2)$ & $200(10.3)$ & $0.93(0.82-1.07)$ & $0.93(0.77-1.13)$ & $0.94(0.78-1.14)$ \\
\hline \multicolumn{6}{|l|}{ Perceived risk occasional smoking } \\
\hline No/slight risk & $602(41.4)$ & $777(40.2)$ & 1 & 1 & 1 \\
\hline Moderate/great risk & $814(56.0)$ & $1097(56.7)$ & $1.00(0.92-1.07)$ & $0.97(0.87-1.08)$ & $1.02(0.92-1.14)$ \\
\hline Do not know & $37(2.5)$ & $61(3.1)$ & $1.22(0.88-1.70)$ & $1.22(0.73-2.04)$ & $1.21(0.78-1.88)$ \\
\hline \multicolumn{6}{|l|}{ Perceived risk regular smoking } \\
\hline No/slight risk & $169(11.6)$ & $223(11.5)$ & 1 & 1 & 1 \\
\hline Moderate/great risk & $1248(85.8)$ & $1655(85.6)$ & $1.00(0.92-1.07)$ & $1.00(0.86-1.17)$ & $0.96(0.81-1.15)$ \\
\hline Do not know & $37(2.5)$ & $56(2.9)$ & $1.22(0.88-1.70)$ & $1.06(0.63-1.76)$ & $0.92(0.57-1.51)$ \\
\hline
\end{tabular}


TABLE 1 Continued

Sample characteristics

Poisson regression results current smoking

$2015 \quad 2019$

n (\%) n (\%)

Total adjusted IRR

$(95 \% \mathrm{Cl})$
Male adjusted IRR

$(95 \% \mathrm{Cl})$
Female adjusted IRR

$(95 \% \mathrm{Cl})$

\begin{tabular}{lccccc}
\hline Peer smoking & & & & & \\
$\quad$ None & $478(33.4)$ & $558(29.8)$ & 1 & $0.99(0.89-1.11)$ & 1 \\
\hline A few/some & $802(56.1)$ & $1125(60.1)$ & $1.00(0.92-1.08)$ & $1.01(0.90-1.13)$ & $1.33(1.13-1.57)^{\star}$ \\
\hline Most/all & $150(10.5)$ & $188(10.1)$ & $1.20(1.06-1.35)^{\star}$ & $1.08(0.92-1.28)$ & \\
\hline ESPAD: European School Survey Project on Alcohol and other Drugs; N/A: not applicable. * : statistical significance at $p<0.05$.
\end{tabular}

2019, respondents perceived increased difficulty in accessing cigarettes and increased family wealth, and reported increased parental education.

Sample characteristics that did not change significantly between 2015 and 2019 were perceived risk from occasional or regular smoking, peer smoking, truancy, household composition, familial regulation, and relationship with mother. Students who had ever-used e-cigarettes were significantly more likely to be current smokers and this risk was more pronounced for boys (IRR 1.33, 95\% CI 1.17-1.51) than for girls (IRR 1.27, 95\% CI 1.11-1.45). Similarly, current-use of e-cigarettes was significantly associated with increased risk of current smoking for both girls and boys and the risk was much higher for girls (IRR 1.49, 95\% CI 1.26-1.75) than for boys (IRR 1.39, 95\% CI 1.21-1.60).

Students from two-parent and blended families were less likely to be current smokers than those from single-parent families (IRR 0.90, 95\% CI 0.83-0.98 and IRR 0.84, 95\% CI 0.71-0.99, respectively), significantly so for male students in two-parent families (IRR 0.88, 95\% CI 0.78-0.99).

Truancy was significantly associated with current smoking, with students who reported that they skipped five or more days of school being more likely to be current smokers (IRR 1.53, 95\% CI 1.32-1.78). Again, the risk was more pronounced for boys (IRR 1.61, 95\% CI 1.33-1.96) than for girls (IRR 1.46, 95\% CI 1.14-1.86).

Students who reported that most/all of their friends smoked were more likely to be current smokers than were those who had no smoking friends (IRR 1.20, 95\% CI 1.06-1.35) and this was more pronounced for girls (IRR 1.33, 95\% CI 1.13-1.57) than for boys (IRR 1.08, 95\% CI 0.92-1.28).

We examined the increase in current smoking in 15-16-year-olds in Ireland between 2015 and 2019 and found that it was associated with e-cigarette use, truancy, household composition, familial regulation, and peer smoking. Consistent with Perelman et al. [3] and previous Irish ESPAD findings [2, 4], the risks of current smoking were higher among those who reported truancy and were higher still among boys who reported skipping school more than five times.

Household composition has previously been associated with current smoking [4, 5], with students from two-parent families being less likely to smoke than those from single-parent families. We provide partial confirmation for these findings in relation to boys only, with boys from two-parent families, and also from blended families, being significantly less likely to report current smoking than boys from single-parent families. We confirm our previous findings showing an association between familial regulation and current smoking [4]. We recommend therefore that smoking intervention and prevention programmes be cognisant of family structure as well as gender [6].

Having peers who smoke is positively associated with teenage current cigarette smoking $[7,8]$. The risks of smoking are higher for students who report that most or all their friends smoke than for those with no friends who smoke, and higher for girls than for boys. Liu et al. [9], in a meta-analysis of 75 longitudinal teen smoking studies, found that having friends who smoke doubles the risk that youths aged 10 to 19 years will smoke. Our findings highlight the importance of making adolescents aware of, and attentive to, the role that friends play in their smoking initiation [10].

In Ireland, successive policy and legislative initiatives have led to teenagers' access to cigarettes decreasing [6]. Our previous studies showed the association between perceived access to cigarettes and current cigarette 
smoking among adolescents [1], and our current study shows that teenagers perceive access to cigarettes to have become more difficult.

The significant increase in cigarette smoking among teenagers in Ireland in 2019 suggests that further regulatory restrictions are needed to limit access by teenagers to tobacco products $[10,11]$. This could be done by increasing the age for purchase of cigarettes to 21 years of age as has been done elsewhere [12], and also by extending restrictions on where smoking is allowed [10, 13].

Our findings show a negative effect of e-cigarette ever-use on teenagers' likelihood of current smoking. When the model controlled for various factors associated with smoking, e-cigarette ever-use had an additional negative effect, increasing the risks of being a current smoker for both boys and girls. E-cigarette current-use also increased the risk for current smoking for both boys and girls. Our findings support the need for the extension of tobacco control legislation regarding minors to include e-cigarettes. This may be desirable to prevent exposure to second-hand aerosol [14], but also because of the possible renormalisation of smoking [9].

We saw an increase in current cigarette smoking associated with an increasing use of e-cigarettes. Other associated factors did not deteriorate between 2015 and 2019, and access to cigarettes was perceived to have become more difficult during that period. We suggest that our findings highlight the negative impact that increased youth e-cigarette use had on current teenage cigarette smoking. We further suggest that this increase in e-cigarette use by teens poses a threat to the Tobacco Free Ireland policy goal of a smoking prevalence less than $5 \%$ by 2025 [1].

\section{Salome Sunday, Joan Hanafin and Luke Clancy}

TobaccoFree Research Institute Ireland, TUDublin, Dublin, Ireland.

Corresponding author: Luke Clancy (Iclancy@tri.ie)

Acknowledgements: We wish to acknowledge the important part played by colleagues Sheila Keogan, who managed and supervised both Irish waves of ESPAD 2015 and 2019; and Keishia Taylor, Kate Babineau, Ellen Whelan and Ermelinda Furtado da Luz Brzychcyk, who were involved in the data collection and management of the two waves.

Provenance: Submitted article, peer reviewed.

Author contributions: S. Sunday performed the initial analysis and wrote the first version of the manuscript; J. Hanafin and L. Clancy conceptualised the structure, and agreed the methodology and the content of the study. All authors contributed to the development of the manuscript, and read and approved the final version. L. Clancy acquired the funding, and was responsible for resources and supervision.

Support statement: We thank the RCDH Trust and the Dept of Health Ireland for their financial support. Funding information for this article has been deposited with the Crossref Funder Registry.

Conflict of interest: None declared.

\section{References}

1 Li S, Levy D, Clancy L. Tobacco Free Ireland 2025: SimSmoke prediction for the end game. Tob Prev Cessat 2018; 4: 23.

2 Sunday S, Keogan S, Hanafin J, et al. ESPAD 2019 Ireland: Results from the European Schools Project on Alcohol and Other Drugs in Ireland. Dublin, TFRI, 2020.

3 Perelman J, Leão T, Kunst AE. Smoking and school absenteeism among 15- to 16-year-old adolescents: a cross-section analysis on 36 European countries. Eur J Public Health 2019; 29: 778-784.

4 Clancy L, Taylor K, Babineau K, et al. ESPAD 2015: European School Survey Project on Alcohol \& Other Drugs in Ireland. Ireland, TFRI for the Department of Health, 2016.

5 Brown SL, Rinelli LN. Family structure, family processes, and adolescent smoking and drinking. J Res Adolesc 2010; 20: 259-273. 
6 Li S, Keogan S, Clancy L. Does smoke-free legislation work for teens too? A logistic regression analysis of smoking prevalence and gender among 16 years old in Ireland, using the 1995-2015 ESPAD school surveys. BMJ Open 2020; 10: e032630.

7 Li S, Keogan S, Taylor K, et al. Decline of adolescent smoking in Ireland 1995-2015: trend analysis and associated factors. BMJ Open 2018; 8: e020708.

8 Reid JL, Manske SR, Leatherdale ST. Factors related to adolescents' estimation of peer smoking prevalence. Health Educ Res 2007; 23: 81-93.

9 Liu J, Zhao S, Chen X, et al. The influence of peer behavior as a function of social and cultural closeness: a meta-analysis of normative influence on adolescent smoking initiation and continuation. Psychol Bull 2017; 143: 1082-1115.

10 Hanafin J, Clancy L. Youth Smoking in Europe Strategies for Prevention and Reduction. Dublin, TFRI, 2019.

11 US Department of Health and Human Services. Efforts to prevent and reduce tobacco use among young people. Preventing Tobacco Use Among Youth and Young Adults: A Report of the Surgeon General. Atlanta, USDHHS, Centers for Disease Control and Prevention, National Center for Chronic Disease Prevention and Health Promotion, Office on Smoking and Health, 2012; pp. 631-845.

12 Nuyts PAW, Kuipers MAG, Willemsen MC, et al. An increase in the tobacco age-of-sale to 21: for debate in Europe. Nicotine Tob Res 2020; 22: 1247-1249.

13 Fernandez E, Martinez C. Spain: COVID-19 prompts smoking regulation in streets and terraces. https://blogs. bmj.com/tc/2020/09/05/spain-covid-19-prompts-smoking-regulation-in-streets-and-terraces/ Date last updated: 5 September 2020.

14 Amalia B, Liu X, Lugo A, et al. Exposure to secondhand aerosol of electronic cigarettes in indoor settings in 12 European countries: data from the TackSHS Survey. Tob Control 2020; 30: 49-56. 